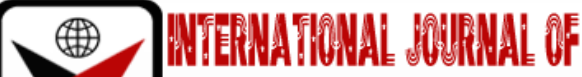

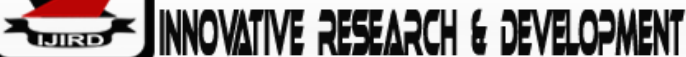

ISSN 2278-0211 (Online)

\section{Evaluation of the Proximate and Elemental Composition of Traditional and Industrial Produced Vinegar}

Osuala Oluchi Judith
Lab Technologist, Department of Pharmaceutical Microbiology and Biotechnology,
Madonna University,USA
Ezemba, Arinze S
Student, Department of Applied Microbiology and Brewing,
Nnamdi Azikiwe University Awka, Nigeria
Ajeh, Joseph Ebuka
Student, Department of Microbiology,
Chukwuemeka Odumegwu Ojukwu University Uli, Nigeria
Chude, Charles Onuorah
Lecturer, Department of Microbiology,
Chukwuemeka Odumegwu Ojukwu University Uli, Nigeria
Ezemba Chinyere Constance
Senior Lecturer, Department of Microbiology,
Chukwuemeka Odumegwu Ojukwu University Uli, Nigeria

\begin{abstract}
:
The vinegar produced from different locally grown fruits and industrial produced vinegar was evaluated to determine their proximate and elemental composition. The proximate parameters analysed includes moisture content, total solids, crude protein, crude fat, crude fibre, carbohydrates and ash content. The elemental composition was determined using Inductively Coupled Plasma Optical Emission Spectrometer (ICP-OES). The moisture content of Vin $A, B, C$ and $D$ are $85.00 \%, 78.30 \%, 90.35 \%$ and $90.65 \%$ respectively. The crude protein in Vin $A, B, C$ and $D$ are $0.20 \pm 0.0001,0.94 \pm 0.020 .69 \pm 0.05$ and $0.64 \pm 0.003$ respectively. The total solid contents of Vin $A, B, C$ and $D$ are $15.00 \pm 0.02,21.7 \pm 0.03,9.65 \pm 0.001,9.35 \pm 0.2$ respectively. The content of crude fat in Vin $A, B, C$ and $D$ are $3.0 \pm 0.0611$, $9.0 \pm 0.33,3.0 \pm 0.02$ and $1.40 \pm 1.0$ respectively. The content of carbohydrates in Vin $A, B, C$ and $D$ are $9.63,4.16,4.36$ and 4.96 respectively. The content of crude fibre in Vin $A, B, C$ and $D$ are $8.00 \pm 0.01,1.40 \pm 0.714 .00 \pm 0.2$ and $4.00 \pm 0.004$ respectively. The content of crude ash in Vin $A, B, C$ and $D$ are 2.17 $\pm 0.02,7.60 \pm 0.341 .65 \pm 0.02$ and $2.30 \pm 0.14$ respectively. A total of 69 elements were evaluated for their composition in the sample. In Vin A, the calcium, magnesium, potassium, sodium, phosphorus and sulphur components were detected in the concentration as follows 27.04 ppb, 1.88ppb, 91.2ppb, 3.44ppb, 5.1ppb and 1229.4ppb respectively. In Vin B, their concentration is as follows 4.4422pp, 0.7580ppb, 39.8348ppb, 3.468ppb, 1.5508ppb, 1277.8402ppb. In Vin C, their concentration detected were as follows 29.4103ppb, 3.5820ppb, 115.6922ppb, 5.4867ppb, 3.2771ppb, 1230.3251ppb respectively and in Vin $D$, the components were detected in the concentration as follows 5.3955ppb, 1.1293ppb, 69.6028ppb, 4.3505ppb, $3.1667 p p b, 1226.3422 p p b$ respectively. The micronutrients were detected at different concentration but mainly in minute quantities. The vinegar samples are of good nutritional value and as such be encouraged to be consumed.
\end{abstract}

Keywords: Elemental Composition, micronutrients, crude fibre, carbohydrates and ash content

\section{Introduction}

Vinegar is a liquid suitable for human consumption produced through the process of fermentation of starch and sugars. It is has a lot of importance like it can be used to marinate meats, pickling of vegetables, other food-stuffs, and boosts the functionality of our immune system. Vinegar can be made using different methods from various raw materials and the main requirement being satisfactory economic source of alcohol (Ezembaet al., 2021). The wine (white, red, and sherry wine), fruit, cider, pure ethanol, musts, malted barley, etc. are used as raw materials for vinegar production. Acetic acid is the significant flavoring and antimicrobial component of vinegar. Ethanol can be oxidized to acetic acid by acetic acid bacteria, a group of obligate aerobic gram negative bacteria (Saha and Banerjee, 2013).

The production of vinegar typically involves alcoholic fermentation, where simple sugars in raw material are converted to alcohol by yeasts. The resultant alcohol is further oxidized to acetic acid by AAB during the last fermentation (acetic fermentation) (Gullo and Giudici 2008).Fermented juices from a wide variety of fruits (other than grapes) can also 
be used to produce vinegar. Although high quality products are produced from fresh and high quality juice fruit, it is technically feasible to produce them from second quality fruit and even waste fruit (Monspart-Sényi, 2006). However, the main reason that fruits are not commonly used to produce fruit vinegar is their low sugar content. Despite the similarities between the processes and the long tradition and knowledge available regarding the elaboration of wine vinegars, this process is not fully comparable to the production of fruit vinegars. Apart from the differences in sugar concentration between fruits, there are other factors to be considered as well. These factors include the difficult extraction required to obtain the juice of some fruits, which leads to the use of commercial pectinolytic enzymes, and the high concentration of organic acids in some fruits, which can hinder the growth of some microorganisms. It is important to note that many fruit vinegars are made by distillation of an alcoholic solution, and the further addition of fruit juice or fruit puree is provided for their aromatization. These types of "non-natural" fruit vinegar are commonly available in some Asian countries, such as China, where the market has no specific regulations for this type of product (Chang et al., 2005). Even in Europe, clear regulation of these products does not exist. In recent years, different studies have been conducted on these products that mainly focused on their organoleptic characteristics and their quality parameters, which has been analyzed by chemical and sensory methods. Some examples include the studies carried out with rabbit eye blueberry (Min-Sheng and Po-Jung, 2010), apple (Liu et al., 2008; Sakanaka and Ishihara, 2008), lemon, peach (Liu et al., 2008), persimmon (Sakanaka and Ishihara, 2008; Ubedaet al., 2011b), plum (Liu and He, 2009), and strawberry (Ubedaet al., 2011a), mix fruit (Ezembaet al., 2021) vinegars.

The trend in consuming vinegar in Nigeria is on the increase, and in as much as so many benefits have been observed in the use of vinegar, little attention has been given to the locally produced vinegar from locally grown fruits. It is therefore for this reason that up till this moment, we still deal on industrially produced vinegar whose nutritional facts are yet to be verified and also very expensive, It is necessary therefore to access the locally grown fruits in vinegar production as well as solve issues relating to expense and consequently improve the economy of the country since these fruits whether spoilt or fresh is a great substrate for vinegar production (Ezembaet al., 2021).

Nutritional researchers have encouraged the regular consumption of bioactive substances and the functional food properties of vinegar have been reported in a variety of scientific and lay publications. With the publications on the health benefits of vinegar, a contemporary increase in demand for fruit vinegar production has occurred (Mazza and Murooka, 2009; Ou and Chang, 2009). The aim of this research is to evaluate the proximate and elemental constituent of the traditional and industrial produced vinegar.

\section{Materials and Methods}

\subsection{Procurement of Materials}

The local and industrial vinegar samples produced using the method by Ezembaet al (2021) was procured at Chychy Gilgal Ltd laboratory and consultancy services, Ichida. The vinegar samples procured were labeled Vin A, Vin B and VinC based on the raw materials used while the industrial produced vinegar Bragg (organic) raw unfiltered apple cider vinegar with mother was produced from Awka.

- Vin A = vinegar from combination of lemon, lime, orange, grape (all with the peel)

- Vin $B=$ vinegar from combination of green and red apple with the peels bought from Awka

- Vin $C=$ vinegar from vinegar from pawpaw, jackfruit, pineapple with peel and oranges

- Vin $\mathrm{D}=$ Bragg (organic) raw unfiltered apple cider vinegar with mother.

\subsection{Proximate Analysis}

\subsubsection{Crude Protein Determination}

For the digestion process, $10 \mathrm{mLs}$ of distilled water, $12 \mathrm{mLs}$ of concentrated sulphuric acid, and two pieces of Kjeldahl tablets and $1 \mathrm{~mL}$ of samples were inserted into a digestion tube. The tubes used for the digestion were placed in an insert rack of the control unit and heated at $400{ }^{\circ} \mathrm{C}$ for $1 \mathrm{hr}$. The samples were cooled for at least 30 min in a fume hood.

The digest is diluted with $200 \mathrm{ml} \mathrm{ofNH}{ }_{3}$ - free water. Alkali-containing $50 \%$; sodium thiosulphate $(10 \mathrm{ml})$ is added to neutralize the sulphuric acid. The ammonia formed is distilled into a boric acid solution containing the indicators.The receiver solution was prepared by dissolving $4 \mathrm{~g}$ of Boric acid in $100 \mathrm{ml}$ distilled water to make $4 \%$ Boric acid for distillation process. $1 \mathrm{~mL}$ Bromocresol green and $0.7 \mathrm{~mL}$ methyl red were added and stirred on a stirring hotplate at medium temperature to dissolve completely. $30 \mathrm{mLs}$ from the solution was then added into each receiver flask to starts the analysis (distillation process) until the receiver solution in the conical flask turned from red to green colour. The flask was removed and titration was carried out against $0.1 \mathrm{~N}$ Hydrochloric acid $(\mathrm{HCl})$ for determination of Kjeldahl nitrogen, which gives the protein content. The nitrogen percentage was calculated by the following formula:

$\mathrm{N} \%=$ (ml of sample $-\mathrm{ml}$ of blank) $\mathrm{x}$ normality of $\mathrm{HCl} \times 14.007 \times 100$

Weight of sample (mg)

Thus, protein content was estimated by conversion of nitrogen percentage to protein

Protein $\%=\mathrm{N} \% \mathrm{x}$ Conversion factor $(6.25)$

Where conversion factor $=100 / \mathrm{N}$ (N\% in fruit products) (Seri et al., 2016). 


\subsubsection{Carbohydrate}

This was calculated by difference according to AOAC 2006. The sum of percentage of moisture, fat, protein and ash were subtracted from $100 \%$

$\%$ Carbohydrate $=100-(\%$ Protein $+\%$ Moisture $+\%$ fat $+\%$ Ash $)$.

\subsubsection{Moisture Content}

The moisture content of the samples was determined using thermal drying method. Weiging of $10 \mathrm{mLsof}$ the vinegar sample was made in triplicate and placed in crucibles. Empty crucibles were first washed, dried, weighed and then being filled $10 \mathrm{mLs}$ of the samples and then placed in an oven for drying at $105^{\circ} \mathrm{C}$ for $3 \mathrm{hr}$, allowed to cool in a desiccator and then reweighed. The percentage moisture content was calculated by the following formula:

$\%$ moisture $=\mathrm{W} 1-\mathrm{W} 2 \times 100$

Where, $\mathrm{W} 1=\mathrm{We} \_\mathrm{W} 1$ ample before drying $\mathrm{W} 2=$ Weight of sample after drying

(AOAC 2006).

Total solid contents

Determination of crude fat

: Total solids were estimated by deducting percentage of moisture from hundred

: Ten grams of the vinegar was measured into a beaker. $30 \mathrm{mLs}$ of $\mathrm{n}$-hexane was added into the beaker containing the sample and stirred vigorously and filtered into an already weighed flask. The process is repeated 5 times. The $n$-hexane is collected using the soxhlet extractor. The flask containing the crude fat is dried and allowed to cool in a desiccator. The readings are taken using the formula

$\%$ crude fat $=\mathrm{W} 1-\mathrm{W} 2$

Where W3 ei६ 1

with sample after drying; $\mathrm{W} 2=$ weight of empty flask;

(AOAC 2006).

W3=sample weight

- Determination of crude fibre: One gram of the sample was weighed accurately into a $250 \mathrm{~mL}$ conical flask. An addition of $50 \mathrm{~mL} 0.3 \mathrm{~N} \mathrm{H}_{2} \mathrm{SO} 4$ was made and refluxed for half hour using air condenser. After the $1 / 2 \mathrm{hr}, 50 \mathrm{~mL} 1.5 \mathrm{~N}$ $\mathrm{NaOH}$ was added and refluxed for another $1 / 2 \mathrm{hr}$. The flask was removed from the heater and filtered. The flask was rinsed with hot distilled water into the same filter paper. Then residue was washed on the filter paper with $50 \mathrm{ml}$ $0.3 \mathrm{~N} \mathrm{HCL}$, followed with 5 times washings with hot distilled water. Finally the residue was wash with $50 \mathrm{ml}$ acetone to remove any fat present. The residue (fibre) was scraped using a jet of acetone from the paper into clean platinum dish. Care was taken to transfer all the fibre into the dish. The acetone was evaporated off by heating the dish on a hot boiling water bath. Then the dish was dried for $1 \mathrm{hr}$ at $140^{\circ} \mathrm{C}$. Cool and weigh $\left(\mathrm{W}_{1}\right)$. The fibre was ashed at $700^{\circ} \mathrm{C}$ in a furnace for $1 \mathrm{hr}$. Cool and weighed $\left(\mathrm{W}_{2}\right)$.

- Calculation: The difference between the two weighing of the dish divided by the weight of the sample, multiplied by 100 is the $\%$ crude fibre

$$
\% \text { CrudeFibre: } \frac{\text { Wtofdish }+ \text { Fibre }\left(W_{1}\right)-A s h\left(W_{2}\right)}{\text { WtofSample }} \times 100 \%
$$

(AOAC 2006).

- Determination of Ash content: About 5 mLof each of the sampleswere measured into a weighed crucible. The crucibles were placed in a muffle furnace and ignited to start the ashing process for 12 hours at about $5500^{\circ}$ Cafter which the furnace was put off and allowed to cool to atleast $250^{\circ} \mathrm{C}$ an $\mathrm{d}$ the furnace door was carefully opened to avoid fluffing out of ashes and using a safety tong, the crucibles were removed and transferred into a desiccator and allowed to cool before weighing.

The ash content is calculated as follows:

- $\quad$ Calculation: $\%$ ash =

$$
\frac{\text { WeightAfterAshing }(W 3)-\text { TareWeightofCrucible }(W 1)}{\text { OriginalSampleWeight }(W 2) \times \text { DryMatterCoefficient }} \times 100 \%
$$

(AOAC 2006).

\subsection{Elemental Analysis Using Agilent 720 Inductively Coupled Plasma Optical Emission Spectrometer (ICP-OES)}

The instrument was first set up by ensuring that the exhaust line is secured, the gas lines were connected and the gas supplies are turned on and checking that all tubing on the spray chamber, nebulizer, and peristaltic pumps are correctly connected. The power supply/High voltage switch/ auto-sampler was turned on and the instrument (ICP-OES 720), computer, ICP-OES software interface was turned on and allowed for 10 minutes for initialization. The Plasma Enable Switch was placed in the Enable State then the instrument was allowed to warm up and initialize for about 10 minutes and rinsed with rinse-solution $\left(2-5 \% \mathrm{HNO}_{3}\right)$. After the setup, the analytical calibration was carried out and the samples were inserted into the auto ampler along with the blanks. Appropriate codes were entered and the analysis began. At the end of sample run, the blank was run and rinse solution for few minutes. The results were saved and the instrument was powered off after about $5 \mathrm{mins}$ of rinse and the result was read. The concentration of the elements in the sample was calculated as ppb. 


\section{Results}

\subsection{Evaluation of Proximate Analysis of the Vinegar Samples}

This analysis gives the nutritional information of the vinegar samples. The samples analysed includes;

Vin $A$ = vinegar from combination of lemon, lime, orange, grape (all with the peel)

Vin $\mathrm{B}=$ vinegar from combination of green and red apple with the peels bought from Awka

Vin $\mathrm{C}=$ vinegar from vinegar from pawpaw, jackfruit, pineapple with peel and oranges

Vin $\mathrm{D}=$ Bragg (organic) raw unfiltered apple cider vinegar with mother.

From the result on table 1 , the moisture content of Vin A, B, C and D are 85.00\%, 78.30\%, 90.35\% and 90.65\% respectively. The crude protein in Vin A, B, C and D are $0.20 \pm 0.0001,0.94 \pm 0.020 .69 \pm 0.05$ and $0.64 \pm 0.003$ respectively. The total solid contents of Vin A, B, C and D are 15.00 $\pm 0.02,21.7 \pm 0.03,9.65 \pm 0.001,9.35 \pm 0.2$ respectively. The content of crude fat in Vin A, B, C and D are 3.0 $\pm 0.0611,9.0 \pm 0.33,3.0 \pm 0.02$ and 1.40 \pm 1.0 respectively. The content of carbohydrates in Vin A, B, C and D are 9.63, 4.16, 4.36 and 4.96respectively. The content of crude fibre in Vin A, B, C and D are 8.00 \pm 0.01 , $1.40 \pm 0.714 .00 \pm 0.2$ and $4.00 \pm 0.004$.

\begin{tabular}{|c|c|c|c|c|c|c|c|}
\hline Sample & $\begin{array}{c}\text { Moisture } \\
\text { (\%) }\end{array}$ & $\begin{array}{c}\text { Total solid } \\
\text { Content (\%) }\end{array}$ & $\begin{array}{c}\text { Crude } \\
\text { Protein (\%) }\end{array}$ & $\begin{array}{c}\text { Crude Fat } \\
\mathbf{( \% )}\end{array}$ & $\begin{array}{c}\text { Crude } \\
\text { Fibre(\%) }\end{array}$ & $\begin{array}{c}\text { Ash } \\
\text { Content } \\
(\%)\end{array}$ & $\begin{array}{c}\text { Carbohydrates } \\
\text { (\%) }\end{array}$ \\
\hline Vin A & $85.00 \pm 0.02^{\mathrm{a}}$ & $15.00 \pm 0.02^{\mathrm{ab}}$ & $0.20 \pm 0.00^{\mathrm{a}}$ & $3.0 \pm 0.06^{\mathrm{b}}$ & $8.00 \pm 0.01^{\mathrm{c}}$ & $2.17 \pm 0.02^{\mathrm{ab}}$ & $9.63 \pm 0.00^{\mathrm{b}}$ \\
\hline Vin B & $78.30 \pm 0.03^{\mathrm{b}}$ & $21.7 \pm 0.03^{\mathrm{b}}$ & $0.94 \pm 0.02^{\mathrm{ab}}$ & $9.0 \pm 0.30^{\mathrm{c}}$ & $1.40 \pm 0.71^{\mathrm{a}}$ & $7.60 \pm 0.34^{\mathrm{c}}$ & $4.71 \pm 0.60^{\mathrm{c}}$ \\
\hline Vin C & $90.35 \pm 0.00^{\mathrm{c}}$ & $9.65 \pm 0.001^{\mathrm{a}}$ & $0.64 \pm 0.00^{\mathrm{b}}$ & $3.0 \pm 0.02^{\mathrm{b}}$ & $4.00 \pm 0.20^{\mathrm{b}}$ & $1.65 \pm 0.02^{\mathrm{a}}$ & $4.36 \pm 0.11^{\mathrm{a}}$ \\
\hline Vin D & $90.65 \pm 0.20^{\mathrm{c}}$ & $9.35 \pm 0.20^{\mathrm{a}}$ & $0.69 \pm 0.05^{\mathrm{b}}$ & $1.40 \pm 1.0^{\mathrm{a}}$ & $4.00 \pm 0.00^{\mathrm{b}}$ & $2.30 \pm 0.14^{\mathrm{b}}$ & $4.96 \pm 0.01^{\mathrm{ab}}$ \\
\hline
\end{tabular}

Table 1: Evaluation of Proximate Analysis of the Vinegar Samples

The values are expressed as mean \pm standard deviation of the measurements. The superscripts with different letters are significantly different at the p-value within the same columns.

Vin $A$ = vinegar from combination of lemon, lime, orange, grape (all with the peel)

Vin $B=$ vinegar from combination of green and red apple with the peels bought from Awka

Vin $C=$ vinegar from vinegar from pawpaw, jackfruit, pineapple with peel and oranges

Vin $\mathrm{D}=$ Bragg (organic) raw unfiltered apple cider vinegar with mother

Vin $A$ and $C$ are locally Produced Vinegar from different fruit mix

Vin B is locally Produced Vinegar from Apple purchased in the local market

Vin D is sample of industrially produced vinegar

\subsection{Elemental Composition of the Vinegar Samples}

The analysis was conducted to determine the elements present in the samples as well as its composition. The samples analysed are as follows;

Vin $A$ = vinegar from combination of lemon, lime, orange, grape (all with the peel)

Vin $\mathrm{B}=$ vinegar from combination of green and red apple with the peels bought from Awka

Vin $C=$ vinegar from vinegar from pawpaw, jackfruit, pineapple with peel and oranges

Vin $\mathrm{D}=$ Bragg (organic) raw unfiltered apple cider vinegar with mother.

All the samples were analyzed using the Inductively Coupled Plasma Optical Emission Spectrometer (ICP-OES) and a total of 69 elements were evaluated for their composition in the sample as can be seen in table 4 . Calcium, Magnesium, Potassium, Sodium, Phosphorus, sulfur which are macro elements got significant values in the composition of all the vinegar samples as can be seen in table 2. Their values are measured in parts per billion (ppb). In Vin A, the calcium, magnesium, potassium, sodium, phosphorus and sulphur components were detected inthe concentration as follows $27.04 \mathrm{ppb}, 1.88 \mathrm{ppb}, 91.2 \mathrm{ppb}, 3.44 \mathrm{ppb}, 5.1 \mathrm{ppb}$ and $1229.4 \mathrm{ppb}$ respectively. In Vin $\mathrm{B}$, their concentration is as follows 4.4422pp, 0.7580ppb, 39.8348ppb, 3.468ppb, 1.5508ppb, 1277.8402ppb. In Vin C, their concentration detected were as follows 29.4103ppb, 3.5820ppb, 115.6922ppb, 5.4867ppb, 3.2771ppb, 1230.3251ppb respectively and in Vin D, the components were detected in the concentration as follows 5.3955ppb, 1.1293ppb, 69.6028ppb, 4.3505ppb, $3.1667 \mathrm{ppb}, 1226.3422 \mathrm{ppb}$ respectively. The micronutrients were detected at different concentration but mainly in minute quantities. Example zinc, cobalt, copper, iron manganese, molybdenum and selenium. Heavy metals such as lead, mercury, cadmium, and aluminum in addition to the many other heavy metals were detected but at concentrations that are not harmful to the human body. 


\begin{tabular}{|c|c|c|c|c|c|}
\hline & Elements & Vin A (ppb) & Vin B (ppb) & Vin C (ppb) & Vin D (ppb) \\
\hline & Macro Minerals & & & & \\
\hline 1. & Calcium [Ca] 422.673 & 27.0489 & 4.4422 & 29.4103 & 5.3955 \\
\hline 2. & Sodium [Na] 589.592 & 3.4404 & 3.4648 & 5.4867 & 4.3505 \\
\hline 3. & Potassium [K]766.491 & 91.2951 & 39.8348 & 115.6922 & 69.6028 \\
\hline 4. & Magnesium [Mg ]279.553 & 1.8832 & 0.758 & 3.582 & 1.1293 \\
\hline 5. & Phosphorus [P] 213.618 & 5.1756 & 1.5508 & 3.2771 & 3.1667 \\
\hline 6. & Sulfur [S] 181.972 & 1229.424 & 1277.84 & 1230.325 & 1226.342 \\
\hline & Micro and Heavy Minerals & & & & \\
\hline 7. & Lanthanum [La] 333.749 & 0.008 & 0.001 & 0.0068 & 0.0013 \\
\hline 8. & Lutetium [Lu] 261.541 & 0.0002 & -0.0001 & 0.0002 & 0.0001 \\
\hline 9. & Neodymium [Nd]401.224 & -0.0088 & -0.0104 & -0.0082 & -0.01 \\
\hline 10. & $\begin{array}{c}\text { Praseodymium [Pr] } \\
417.939 \\
\end{array}$ & -0.0379 & -0.0351 & -0.0359 & -0.0339 \\
\hline 11. & Samarium [Sm]359.259 & -0.0042 & -0.0047 & -0.0045 & -0.0045 \\
\hline 12. & Scandium [Sc] 361.383 & 0.0001 & 0.0001 & 0.0001 & 0 \\
\hline 13. & Thorim [Th] 283.730 & -0.0007 & -0.0003 & 0.0002 & -0.0003 \\
\hline 14. & Terbium [Tb] 350.914 & -0.0003 & -0.0005 & -0.0007 & -0.0003 \\
\hline 15. & Thulium [Tm] 313.125 & 0.0002 & 0.0005 & 0.0004 & 0.0002 \\
\hline 16. & Uranium [U]385.957 & 0 & 0.0046 & 0.0014 & 0.0025 \\
\hline 17. & Ytterbium[Yb] 328.937 & 0.0002 & 0.0001 & 0.0001 & 0.0001 \\
\hline 18. & Yttrium [Y] 371.029 & 0.0015 & 0.0005 & 0.0016 & 0.0007 \\
\hline 19. & Cerium [Ce] (418.659) & 0.0098 & 0.0111 & 0.0192 & 0.014 \\
\hline 20. & Iridium [Ir] 224.268 & -0.0088 & -0.0095 & -0.0059 & -0.0076 \\
\hline 21. & Palladium [Pd] 340.458 & 0.0004 & 0.0011 & -0.0005 & 0.0014 \\
\hline 22. & Platinum [Pt] 214.424 & -0.014 & -0.013 & -0.0146 & -0.0128 \\
\hline 23. & Rhodium [Rh] 343.488 & -0.005 & -0.0057 & -0.0057 & -0.0081 \\
\hline 24. & Ruthenium [Ru] 267.876 & 0.329 & 0.387 & 0.3027 & 0.2792 \\
\hline 25. & Gold [Au] 242.794 & -0.0032 & -0.0014 & -0.0011 & -0.0037 \\
\hline 26. & Tellurium [Te] 214.282 & -0.0222 & -0.0218 & -0.0193 & -0.0234 \\
\hline 27. & Aluminum [Al] 167.019 & 0.0003 & -0.0006 & 0.0024 & 0.0014 \\
\hline 28. & Arsenic [As] 188.980 & -0.0104 & -0.0114 & -0.0199 & -0.0153 \\
\hline 29. & Barium [Ba] 455.403 & 0.0452 & 0.024 & 0.5887 & 0.035 \\
\hline 30. & Beryllium [Be] 313.042 & 0 & -0.0001 & -0.0001 & -0.0001 \\
\hline 31. & Caesium [Cs] 697.327 & Uncal & Uncal & Uncal & Uncal \\
\hline 32. & Gallium [Ga] 294.363 & -0.0018 & -0.0025 & -0.0061 & -0.0019 \\
\hline 33. & Lithium [Li] 670.783 & -0.0001 & 0.0009 & 0.0001 & 0.0009 \\
\hline 34. & Indium [In] 230.606 & 0.0121 & 0.0005 & -0.0003 & -0.0073 \\
\hline 35. & Dysporium [Dy] (353.171) & 0.0001 & -0.0002 & -0.0008 & -0.0003 \\
\hline 36. & Europium [Eu] 420.504 & 0.0007 & 0.0013 & 0.0014 & 0.0013 \\
\hline 37. & Rubium [Rb] 780.026 & 0.315 & 0.0001 & 0.3948 & 0.0138 \\
\hline 38. & Selenium [Se] 196.026 & -0.0244 & -0.0484 & -0.0357 & -0.045 \\
\hline 39. & Erbium [Er] 349.910 & -0.0006 & -0.0002 & -0.0003 & -0.0013 \\
\hline 40. & Strontium [Sr] 407.771 & 0.1449 & 0.0149 & 0.2976 & 0.017 \\
\hline 41. & Bismuth [Bi] 223.061 & -0.0058 & -0.0092 & -0.0108 & -0.0093 \\
\hline 42. & Antimony [Sb] 206.834 & -0.0081 & -0.0013 & -0.0055 & -0.0077 \\
\hline 43. & Boron [B ]249.772 & 0.2584 & 0.1745 & 0.091 & 0.1535 \\
\hline 44. & Germanium [Ge] 209.426 & -0.0275 & -0.0464 & -0.0317 & -0.0447 \\
\hline 45. & Hafnium [Hf] 264.141 & -0.0013 & -0.0006 & -0.0012 & -0.0012 \\
\hline 46. & Molybdenum [Mo] 202.032 & 0.0716 & 0.0263 & 0.0162 & 0.0065 \\
\hline 47. & Niobium [Nb] 313.078 & 0.0025 & 0.0009 & 0.0013 & 0.0032 \\
\hline 48. & Holmium[Ho] 345.600 & 0.0001 & -0.0005 & -0.0002 & -0.0004 \\
\hline 49. & Rhenium [Re] 227.525 & -0.0012 & -0.001 & -0.0023 & 0 \\
\hline 50. & Silicon [Si ]251.611 & 0.3856 & 0.3215 & 0.4994 & 0.3138 \\
\hline 51. & Gadolinum[Gd] 342.246 & -0.0003 & -0.0007 & -0.0003 & -0.0008 \\
\hline 52. & Tantalum [Ta] 268.517 & 0.0126 & 0.0148 & 0.0032 & 0.0068 \\
\hline 53. & Tin [Sn] 189.925 & -0.0271 & -0.0311 & -0.024 & -0.0261 \\
\hline 54. & Titanium [Ti] 336.122 & 0.0374 & 0.0107 & 0.0174 & 0.0345 \\
\hline 55. & Tungsten [W] 207.912 & -0.0058 & -0.0061 & -0.004 & -0.0056 \\
\hline 56. & Zirconium [Zr] 343.823 & 0.0007 & 0.0003 & 0.0001 & 0.0003 \\
\hline 57. & Cadmium [Cd] 214.439 & -0.0005 & -0.0002 & 0.0009 & -0.0003 \\
\hline
\end{tabular}




\begin{tabular}{|c|c|c|c|c|c|}
\hline & Elements & Vin A (ppb) & Vin B (ppb) & Vin C (ppb) & Vin D (ppb) \\
\hline 58. & Chromium [Cr] 267.716 & 0.6779 & 0.8264 & 0.6527 & 0.6052 \\
\hline 59. & Cobalt[Co] 238.892 & -0.0024 & -0.002 & -0.0021 & -0.0028 \\
\hline 60. & Copper [Cu] 327.395 & 0.0239 & 0.018 & 0.0576 & 0.0206 \\
\hline 61. & Iron [Fe] 238.204 & 0.5041 & 0.6855 & 0.6448 & 0.8285 \\
\hline 62. & Lead [Pb] 220.353 & -0.0187 & -0.0149 & -0.0164 & -0.0103 \\
\hline 63. & Manganese [Mn] 257.610 & 0.0379 & 0.0292 & 0.2746 & 0.0726 \\
\hline 64. & Mercury [Hg] 184.887 & 0.0057 & 0.0081 & 0.0055 & 0.0054 \\
\hline 65. & Nickel [Ni] 231.604 & 0.0035 & 0.0063 & 0.0051 & 0.0028 \\
\hline 66. & Silver [Ag] 328.068 & 0.0064 & 0.0028 & 0.0013 & 0.001 \\
\hline 67. & Thallium [Tl] 190.794 & -0.0189 & -0.0225 & -0.0205 & -0.0158 \\
\hline 68. & Vanadium [V] 292.401 & 0.0051 & 0.0017 & 0.0048 & 0.0022 \\
\hline 69. & Zinc [Zn] 213.857 & 0.0312 & 0.0215 & 0.074 & 0.0438 \\
\hline
\end{tabular}

Table 2: Evaluation of the Elemental Composition of the Vinegar Samples

Vin $A=$ vinegar from combination of lemon, lime, orange, grape (all with the peel)

Vin $B=$ vinegar from combination of green and red apple with the peels bought from Awka

Vin $C=$ vinegar from vinegar from pawpaw, jackfruit, pineapple with peel and oranges

Vin $D=$ Bragg (organic) raw unfiltered apple cider vinegar with mother

Vin $A$ and $C$ are locally Produced Vinegar from different fruit mix

Vin B is locally Produced Vinegar from Apple purchased in the local market

Vin D is sample of industrially produced vinegar

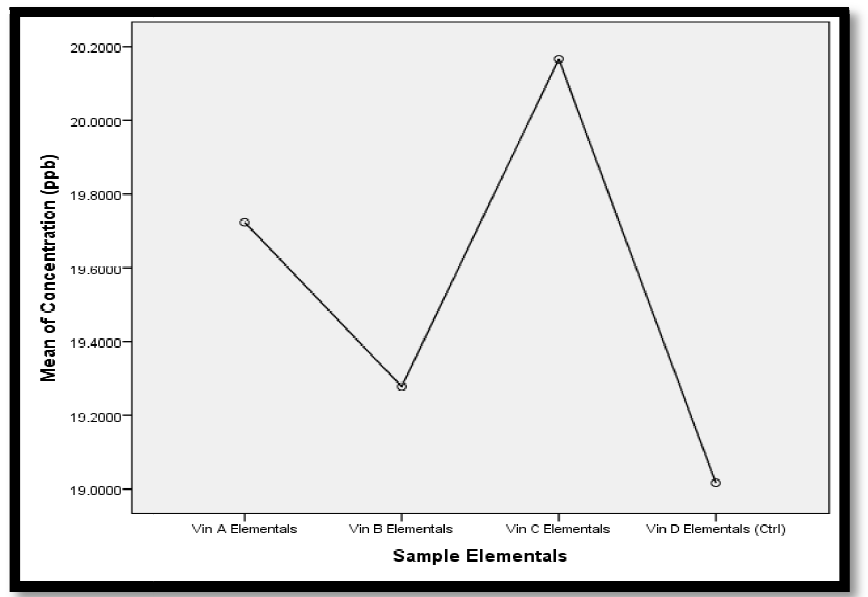

Figure1: Mean of the Elementals of the Vinegar Samples

\section{Discussion}

The proximate analysis data in local fruits vinegar and commercialized vinegar used for present investigation are presented in Table 1. Vin A,B,C and D moisture $85.00 \%, 78.30 \%, 90.35 \%$ and $90.65 \%$ respectively. Vin D had the highest moisture content while Vin B had the lowest. The total solid content components remaining after the removal of moisture. Total solids are measure of the amount of material dissolved in water. This material can include carbonate, bicarbonate, chloride, sulphate, phosphate, nitrate, calcium, magnesium, sodium, organic ions and other ions (American Public Health Association, 1998). The result of total solid content is similar to the result of Umaruet al (2015) in the production of vinegar from pineapple peel wine. Apple cider vinegar has undergone a proper filtering process in factory for the commercialization purpose. Hence the reason why the industrial produced Vin D had the lowest solid content. Thus, it has clear appearance due to absence of residue while for the local fruits vinegars, the conservative filtering process caused the residue to remain. This might be the reason apple cider vinegar has higher moisture content while local fruits vinegar has higher total solid content. This corresponds with the results of Faznira and Seri (2014) in their production of apple cider vinegar.

Carbohydrates, fats and proteins are three main nutrients in foods, which provide energy sources for human body and constitute the structure and content of many cells (Falcone et al., 2007; Chiu et al.,2018.) Reducing sugars and amino nitrogen play an important role in the evaluation of quality in foods (Willett and Stampfer 2013). The content of crude protein in Vin A, B, C and D are $0.20 \pm 0.0001,0.94 \pm 0.020 .69 \pm 0.05$ and $0.64 \pm 0.003$ respectively. Vin B had the highest protein content among the vinegars analysed. The content of crude fat in Vin A, B, C and D are $3.0 \pm 0.0611,9.0 \pm 0.33 .0 \pm 0.02$ and $1.40 \pm 1.0$ respectively. Vin $B$ had the highest crude fat content among the vinegars analysed. The content of carbohydrates in Vin A, B, C and D are 9.63, 4.16,4.36 and 4.96 \pm 0.01 respectively. Vin A had the highest carbohydrate content among the vinegars analysed.

Crude fibre is the organic residue left after subjecting the foodstuff sample to acid and alkali treatment, which are to breakdown the inorganic components. The content of crude fibre in Vin A, B, C and D are 8.00 $\pm 0.01,1.40 \pm 0.714 .00 \pm 0.2$ 
and $4.00 \pm 0.004$ respectively. This result is different from that of Faznira and Seri (2014) with crude fibre of $0.00 \%$ in the apple cider vinegar.

The ash of a foodstuff is the inorganic residue remaining after the organic matter as been burnt away. Ash content represents the total mineral content in foods. It is a part of proximate analysis for nutritional evaluation. The ash content in Vin A, B, C and D are 2.17 $\pm 0.02,7.60 \pm 0.341 .65 \pm 0.02$ and 2.30 \pm 0.14 respectively. These values are generally significantly different from each other. Vin B had the highest ash content among the vinegar analysed followed by Vin A.

The proximate analysis gives the nutritional information of the vinegars analyzed so as to know the nutritional composition of the vinegars.

The nutrients and elements in the vinegars were evaluated to ascertain the quality of the vinegar and also check if it is safe for human consumption.

The calcium content was found highest in Vin C with concentration of 29.41033ppb, followed by Vin A with concentration of 27.0489ppb. Vin B and Vin D have a lesser calcium content. This may be because of the raw materials involved in the in vinegar production as it can be said that the apple cider vinegars have a lower calcium content than the mixed fruit vinegars. The sodium content is highest in Vin C with the concentration of 5.4867ppb followed by Vin D with concentration of $4.3505 \mathrm{ppb}$. The potassium, magnesium and sulfur concentration are highest in Vin C. Phosphorous concentration is highest in Vin A. The presence of micro and heavy elements were evaluated but their concentrations are in minute quantities.

The macro elements in the vinegar samples possess significant values. The elements includes potassium, sodium, magnesium, sulfur, calcium and phosphorus and this agrees with the work of Seri et al (2016) who also presented significant amount of potassium, sodium, calcium, magnesium, manganese, zinc and iron in samples of rambutan vinegar, Dokong vinegar, apple cider vinegar and Nipar vinegar. There work of Dabija and Hatnean (2014), also showed certain elements that are similar to the ones in this work such as lithium, beryllium, boron, sodium, magnesium, aluminum, calcium vanadium, chromium, manganese, iron, nickel, copper, zinc, selen um, rubium, strontium, caesium and Barium but lacked potassium in their study quality of apple cider vinegar obtained from classical methods. This work is in line with so many other reports on elements that have been on different vinegar samples. Fu et al (2013) reported the presence of sodium, magnesium, potassium, calcium, manganese, iron, zinc, strontium, arsenic, chromium, cobalt, nickel, copper, selenium, molybdenum, cadmium, tin, antimony, barium and lead in mature Chinese, white and spiced vinegar. Ozturket al (2015) reported the presence of selenium, chromium, manganese, copper, zinc, sodium, potassium, magnesium, cobalt, calcium and nickel in traditional homade Turkish vinegar from grapes and apples. Ghosh et al (2015) reported the presence of magnesium, calcium, manganese, copper, zinc, sodium, potassium and iron in palm vinegar. Chou et al (2015) have reported the presence of potassium, magnesium, calcium, iron, manganese and selenium from Chinese black vinegar. Panequeet al (2016) reported the presence of aluminium, arsenic, boron, barium, cadmium, cobalt, chromium, copper, iron, potassium, magnesium, manganese, sodium, nickel, phosphorous, lead, sulfur, strontium, vanadium and zinc in Andalusian wine vinegar from grape. Koyama et al (2017) reported the presence of calcium, sodium, potassium, magnesium and iron from tomato vinegar.

Fruits and vegetables continue to be the major sources of nutrients, including proteins, vitamins, macro and essential trace elements, and minerals in human diet for proper growth, body development, and maintenance of overall health and well-being (CMNRIM,1999; NCI,1986; NRC, 1989; WCRF, 1997).

For instance, Calcium and Magnesium are macro elements that are necessary for proper development of bone and structural tissue formation and play important roles in glucose and protein absorption and metabolism (Agarwal et al., 2011). They are also involved in the regulation and dilation of blood vessels and a regular heartbeat (Agarwal et al., 2011). Deficiency of them has been widely associated with weak bones and structural connective tissue formation, hypertension, and poor glucose absorption and utilization (Koschet al., 2001). Iron (Fe) is a vital component of heme proteins, hemoglobin, and myoglobin (Fraga, 2005) required for oxygen transportation, proper cellular metabolism, glucose metabolism, and vascular functions (Fernandez-Real et al., 2002). Fe deficiency in humans has been shown to lead to a host of health issues such as a weakened immune system, inhibition of hemoglobin synthesis, which leads to anemia, insomnia, and other health related complications (Tapieroet al., 2001).

Other essential trace or micro elements such as Zinc, Copper, Manganese, and Selenium found in the vinegar also play important roles in maintaining proper human health. For instance, Zinc is an important element in the human body, serving as a cofactor in anumber of enzymatic reactions and responses such as metallo-enzymes for carboxyl peptidase, liver alcohol dehydrogenase, and carbonic anhydrase (Prasad, 2012). Copper is a coenzyme and crucial cofactor in Fe utilization, collagen amalgamation, and concealment of free radicals, and required for redox chemical cytochrome oxidase (Arredondo and Nu', nez, 2005; Naismith et al., 2009). Manganese is needed for the immune system and effective food metabolism, serves as a cofactor in numerous enzymatic responses, and aids in blood clotting and hemostasis (Smith et al., 2013). Selenium is essential for chemical responses for glutathione and thyroxine and has also been shown to have anticancer effects (Bangladesmet al., 2016). Nickel (Ni) is moderately required for proper absorption of Fe in the body (Gupta and Gupta, 2014).

The presence of toxic heavy metals can arise due to factors like environmental pollution, industrial activity or the absorption of heavy metals from contaminated soils, industrial effluent, or contaminated irrigation water (Davydova, 2005; Hu et al., 2013; IRAC, 2006; Zaidi et al.,

2005).In respect to this study, toxic heavy metals evaluated include mercury, Cadmium, Arsenic, lead, and Chromium. Their concentrations in the vinegar sample are well below the range that can cause harm on consumption. In contrast to macro and essential trace elements, heavy metals have no nutritional value (Alzahraniet al., 2016). 
With the result presented, Itcan be concluded that there is no significant differencein the proximate and elemental compositionof the Industrial and locally produced vinegar and with their nutritionalInformation, their consumption should be encouraged

\section{References}

i. Agarwal, A., Khanna, P., Baidya, D.K. and Arora, M.K. (2011). Trace elements in critical illness. Journal of Endocrinology and Metabolism. 1:57-63.

ii. Alzahrani H. R., Kumakli, H., Ampiah, E., Mehari, T., Thornton, A.J. Babyak, C. M and Fakayode, S. 0. (2016). Determination of macro, essential trace elements, toxic heavy metal concentrations, crude oil extracts and ash composition from Saudi Arabian fruits and vegetables having medicinal values.Arabian Journal of Chemistry.1:907-913.

iii. American Public Health Association. (1998). Standard Methods for the Examination of Water and Wastewater, 20:127-131.

iv. Arredondo, M., and Nu', nez, M.T. (2005). Iron and copper metabolism. Molecular Aspects of Medicine. 26 (4-5): 313-327.

v. Association of Analytical Chemists (AOAC) (2000). Official methods of analysis (17thed). Washington DC.

vi. Bangladesm, M.H., Moghal, M.R., Sarwar, S., Anonna, S.N., Akter, M., Karmakar, P., Ahmed, S., Sattar, M.A. and Islam, M.S. (2016). Low serum selenium concentration is associated with preeclampsia in pregnant women. Journal of Trace Elements in Medicine and Biology. 33: 21-25.

vii. Chang, R. C., Lee, H. C. and Ou, A. S. M. (2005). Investigation of the Physicochemical Properties of Concentrated Fruit Vinegar. Journal of Food and Drug Analysis. 13: 348-356

viii. Chiu, Y.H.; Chavarro, J.F. and Souter, I. (2018). Diet and female fertility: Doctor, what should I eat? Fertility and Sterility. 110: 560-569.

ix. Chou, C. H., Liu, C. W., Yang, D. J., Wu, Y. H. and Chen, Y. C. (2015). Amino acid, mineral, and polyphenolic profiles of black vinegar, and its lipid lowering and antioxidant effects in vivo. Food Chemistry. 168: 63 -69

x. Committee on Military Nutrition Research (CMNR): Institute of Medicine, 1999. The role of Protein and Amino Acids in Sustaining and Enhancing Performance.

xi. Dabija, A.andHatnean, C.A. (2014).Study concerning the quality of apple vinegar obtained through classical method.Journal of Agroalimentary Processes and Technologies.20(4): 304-310

xii. Davydova, S., (2005). Heavy metals as toxicants in big cities. Microchemical. Journal. 79: 133-136.

xiii. Ezemba A.S, Osuala O.J., Orji M.U., Ezemba C.C., Anaukwu C (2021). Production and comparative physicochemical analysis of vinegar from locally grown fruits in Nigeria and industrial produced vinegar. American Journal of Microbiological Research, 9(1): 25-33.

xiv. Falcone, P.M.; Chillo, S.; Giudici, P. and Nobile, M.A.D. (2007). Measuring rheological properties for applications in quality assessment of traditional balsamic vinegar: Description and preliminary evaluation of a model. Journal of Food Engineering. 80: 234-240.

xv. Faznira, Z A and Seri, I. M. (2014). Comparisons of the proximate values, mineral elements and heavy metals contents in three local fruits vinegars with the apple cider vinegar. International conference on food innovation.1:1-7

xvi. Fernandez-Real, J.M., Lopez-Bermejo, A., and Ricart, W. (2002). Cross talk between iron metabolism and diabetes. Diabetes. 51:2348-2354.

xvii. Fraga, C.G., (2005). Relevance, essentiality and toxicity of trace elements in human health. Molecular Aspects of Medicine. 26: 235-244.

xviii. Fu, L., Nie, X. D., Xie, H. L. and Ferro, M. D. (2013). Rapid multi-element analysis of Chinese vinegar by sector field inductively coupled plasma mass spectrometry. European Food Research and Technology. 237: 795-800.

xix. Ghosh, S., Chakraborty, R., Chatterjee, A. and Raychaudhuri, U. (2015). Optimization of media components for the production of palm vinegar using response surface methodology. Journal of the Institute of Brewing. 120: 550-558.

xx. Gullo, M. and Giudici, P. (2008). Acetic acid bacteria in traditional balsamic vinegar: Phenotypic traitsrelevant for starter cultures selection. International Journal of Food Microbiology125:46-53.

xxi. Gupta, U.C., Gupta, S.G., 2014. Sources and deficiency diseases of mineral nutrients in human health and nutrition: a review. Pedosphere.24 (1): 13-38.

xxii. Hu, J., Wu, F., Wu, S., Cao, Z., Lin, X. and Wong, M.H. (2013). Bioaccessibility, dietary exposure and human risk assessment of heavy metals from market vegetables in Hong Kong revealed with an in vitro gastrointestinal model. Chemosphere.91: 455-461.

xxiii. IRAC. (2006). summaries evaluation: inorganic and organic lead compounds. Monograph for the evaluation of carcinogenic risk to human. International agency for research cancer, Lyon

xxiv. Kosch, M., Hausberg, M., Westerman, G., Koneke, J., Matzies, F., Rahn, K.H. and Kisters, K. (2001). Alterations in calcium and magnesium content of red cell membranes in patients with primary hypertension.American Journal of hypertension. 14:254 - 258

xxv. Koyama, M., Ogasawara, Y., Endou, K., Akano, H., Nakajima, T., Aoyama, T., and Nakamura, K. (2017). Fermentation-induced changes in the concentrations of organic acids, amino acids, sugars, and minerals and superoxide dismutase-like activity in tomato vinegar. International Journal of Food Properties. 20: 888-898.

xxvi. Liu, F and He, Y. (2009). Application of successive projections algorithm for variable selection to determine organic acids of plum vinegar. Food Chemistry. 115: 1430-1436. 
xxvii. Liu, F., He, Y. and Wang, L. (2008). Determination of effective wavelengths for discrimination of fruit vinegars using near infrared spectroscopy and multivariate analysis. Analyticachimicaacta. 615: 10.

xxviii. Mazza, S. and Murooka, Y. (2009). Vinegars through the ages. In: Solieri, L., Giudici, P. (Edition) Vinegars of the World. Italy: Springer-Verlag. 17-39

xxix. Min-Sheng, S. and Po-Jung, C. (2010).Aroma impact components of rabbit eye blueberry (Vacciniumashei) vinegars. Food Chemistry. 119: 923-928.

xxx. Monspart-Sényi, J. (2006). Fruit Processing Waste Management. In: Hui, Y. H. (Eds) Handbook of Fruits and Fruit Processing, Blackwell Publishing, Iowa. 205-215.

xxxi. Naismith, R.T., Shepherd, J.B. and Weihl, C.C. (2009). Acute and bilateral blindness due to opticneuropathy associated with copper deficiency. Archives of Neurology. 66: 1025-1027.

xxxii. National Cancer Institute (NCI), National Institutes of Health, 1986. Diet, Nutrition \& Cancer Prevention: The Good News. NIH Publication No. 87-2878, Bethesda, Maryland, US.

xxxiii. National Research Council (NRC) Committee on Diet and Health; Commission on Life Sciences; Division on Earth and Life Studies. (1989). Diet and Health: Implications for Reducing Chronic Disease Risk.

xxxiv. Ou, A.S.M and Chang, R.C.( 2009). Taiwan fruit vinegar. In: Solieri L., Giudicin P, editors. Vinegars of the world. Mil'an: Springer-Verlag. p 223-224

xxxv. Ozturk, I., Caliskan, O., Tornuk, F., Ozcan, N., Yalcin, H., Baslar, M., and Sagdic, O. (2015). Antioxidant, antimicrobial, mineral, volatile, physicochemical and microbiological characteristics of traditional home-made Turkish vinegars. LWT - Food Science and Technology. 603: 141-151.

xxxvi. Paneque, P., Morales, M. L., Burgos, P., Ponce, L., and Callejón, R. M. (2016). Elemental characterisation of Andalusian wine vinegars with protected designation of origin by ICP-OES and chemometric approach. Food Control. 75: 203-210

xxxvii. Prasad, A.S. (2012). Discovery of human zinc deficiency: 50 years later. Journal of Trace Elements in Medicine and Biology.26: 66-69.

xxxviii. Saha, P. and Banerjee, S. (2013). Optimization of process parametres for vinegar production using banana fermentation..International journal of research in engineering and technology. 2:9

xxxix. Sakanaka, S. and Ishihara, Y. (2008). Comparison of antioxidant properties of persimmon vinegar and some other commercial vinegar in radical-scavenging assays and on lipid oxidation in tuna homogenates. Food Chemistry. 107: 739-744

xl. Seri I. M., Faznira Z. and Mohammad A. (2016).Study On the Nutritional Values And Customer Acceptance OfLansiumdomesticum\&Nepheliumlappaceum Newly Fermented Natural Fruit Vinegars In Malaysia. Second Asia Pacific Conference on Advanced Research. 1:63-74

xli. Smith, E.A., Newland, P., Bestwick, K.G. and Ahmed, N., (2013). Increased whole blood manganese concentrations observed in children with iron deficiency anaemia. Journal of Trace Elements in Medicine and Biology. 27: 65-69.

xlii. Tapiero, H., Gate, L. and Tew, K.D. (2001). Iron: deficiencies and requirements. Biomed. Pharmacother. 55: 324334.

xliii. Ubeda, C., Callejón, R. M., Hidalgo, C., Torija, M. J., Mas, A., Troncoso, A. M. and Morales, M. L. (2011a). Determination of major volatile compounds during the production of fruit vinegars by static gas chromatographymass spectrometry method. Food Research International. 44: 259 -268.

xliv. Ubeda, C., Hidalgo, C., Torija, M. J., Mas, A., Troncoso, A. M. and Morales, M. L. (2011b). Evaluation of antioxidant activity and total phenols index in persimmon vinegars produced by different processes. Food Science and Technology. 44: $1591-1596$.

xlv. Umaru FF, Esedafe WK, Obidah J.S., Akinwotu $O$ and Danba E (2015) Production of vinegar from pineapple peel wine using Acetobacter species. 3rd International Conference on Biological Chemical and Environmental Sciences, Kuala Lumpur (Malaysia). Pg 1-3.

xlvi. Willett, W.C. and Stampfer, M.J. (2013). Current evidence on healthy eating. Annual Review of Public Health. 34: 77-95.

xlvii. World Cancer Research Fund (WCRF), 1997. Food, Nutrition and the Prevention of Cancer. A Global Perspective, Washington, DC.

xlviii. Zaidi, M.I., Asrar, A., Mansoor, A. and Farooqui, M.A. (2005). The heavy metal concentrations along roadside trees of Quetta and its effects on public health. Journal of Applied. Sciences. 5:708-711. 